\title{
Tolerance of the eye for implanted cilia
}

\author{
Guy M Olorenshaw, Anne M V Brooks, Glenys Grant, William E Gillies
} Melbourne, Victoria 3002, Australia G M Olorenshaw A M V Brooks G Grant

W E Gillies

Correspondence to: Street, Melbourne, Victoria 3000, Australia.

Accepted for publication 10 May 1991
Royal Victorian Eye and Ear Hospital, East DrW E Gillies, 82 Collins

\begin{abstract}
Retained cilia in the eye following injury are rare. There are reports of long term tolerance to cilia in the anterior chamber but no information about the effect on the corneal endothelium. A 31-year-old man was seen with a 19-year history of a retained eyelash embedded in a corneal scar and extending across the anterior chamber to the chamber angle. The follicle was absent. There was no cellular inflammatory reaction, and the eye otherwise appeared normal on slit-lamp examination with normal vision. However, there was the appearance of an encrusted deposit on the surface of the lash and a markedly lowered endothelial cell count of $\mathbf{7 5 0}$ cells $/ \mathrm{mm}^{2}$ compared with the fellow eye. The lash was not removed.
\end{abstract}

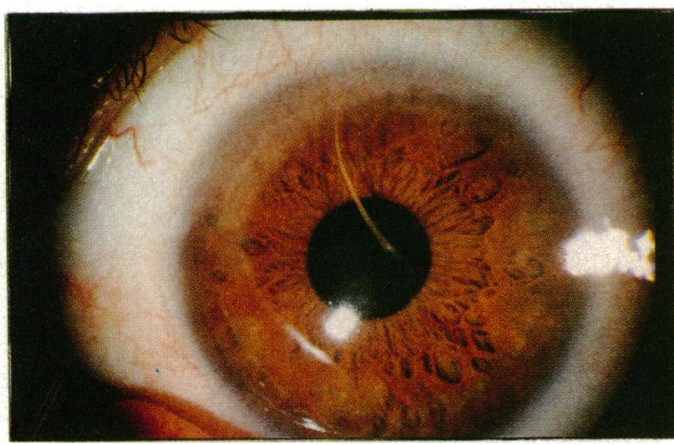

Figure 1 Slit-lamp biomicroscopy of the left eye showing a pale slightly tapering elongated foreign body consistent with an eyelash lying in the anterior chamber extending from a scar close to the visual axis to the angle superiorly. The eye is quiet.

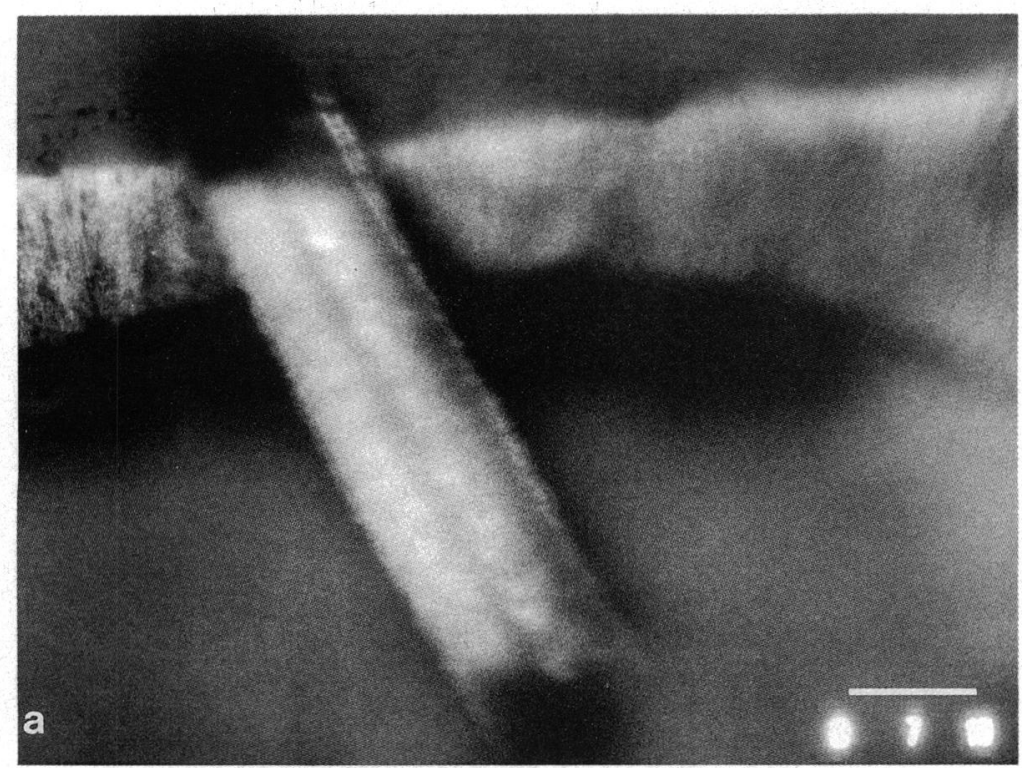

Figure 2 Specular microscopy of left eye showing a cylindrical foreign body running across the anterior chamber with an irregular encrusted surface consistent with deposition of material upon an eyelash. Detail of the iris is seen behind the lash. (Bar=100 $\mu \mathrm{m}$.)
Reports of an eyelash in the eye are uncommon, ${ }^{1}$ though there are reports of remarkably long term tolerance of the eye to cilia. ${ }^{2}$ To our knowledge there are no reports of the effect of retained cilia on the corneal endothelium

\section{Case report}

A 31-year-old man from Luxor, Egypt, presented in July 1990 complaining of long-standing, intermittent, bilateral ocular irritation. He stated that, when aged 12 years, four or five days after an injury to the left eye with a fountain pen tip he was admitted to Luxor Hospital, where one eyelash was removed but another left in the eye. Following intensive antibiotic drops and one outpatient review he had no further trouble until the recent ocular irritation.

On examination vision was right eye $6 / 6$ with $-1.50 \times 5^{\circ}$ and left eye $6 / 6$ with $-1.25 \times 10^{\circ}$. Both eyes showed mild superior corneal pannus and subtarsal scarring. There was a small old full thickness scar in the mid cornea of the left eye, with a pale, elongated, tapering foreign body extending from the upper margin of this scar across to the angle of the anterior chamber at 11 o'clock (Fig 1). The anterior chamber was quiet, with no inflammatory reaction, and both eyes were otherwise normal. Gonioscopy showed the tapered tip of the foreign body lying on the trabecular meshwork with a little surrounding pigmentation.

Specular microscopy showed the oval cross section of a foreign body consistent with an eyelash arising from the upper margin of the old corneal scar (Figs 2,3). The surface had a slightly irregular encrusted appearance suggesting a cocoon of precipitate (Fig 2). The corneal endothelium showed a marked lowering of endothelial cell count $\left(750\right.$ cells $\left./ \mathrm{mm}^{2}\right)$ over the whole endothelial mosaic, with moderate pleomorphism and polymegathism but no signs of active inflammation or oedema (Fig 3). The endothelium in the fellow eye was normal (2700 cells $/ \mathrm{mm}^{2}$ ).

The patient's mild ocular irritation settled with simple topical decongestant drops. No attempt was made to remove the foreign body.

\section{Discussion}

Previous reports of eyelashes retained in the eye include instances of lashes tolerated for a long period with little or no reaction provided the follicle was not included. ${ }^{1-7}$ Delayed inflammatory reactions have been reported, ${ }^{4}$ and lashes in the vitreous or retina have been tolerated, ${ }^{89}$ though others have caused serious consequences. ${ }^{10}$ As early severe reactions to the presence of a lash have been described, ${ }^{1112}$ removal is best in recent cases when the accompanying injury is explored and repaired. How- 


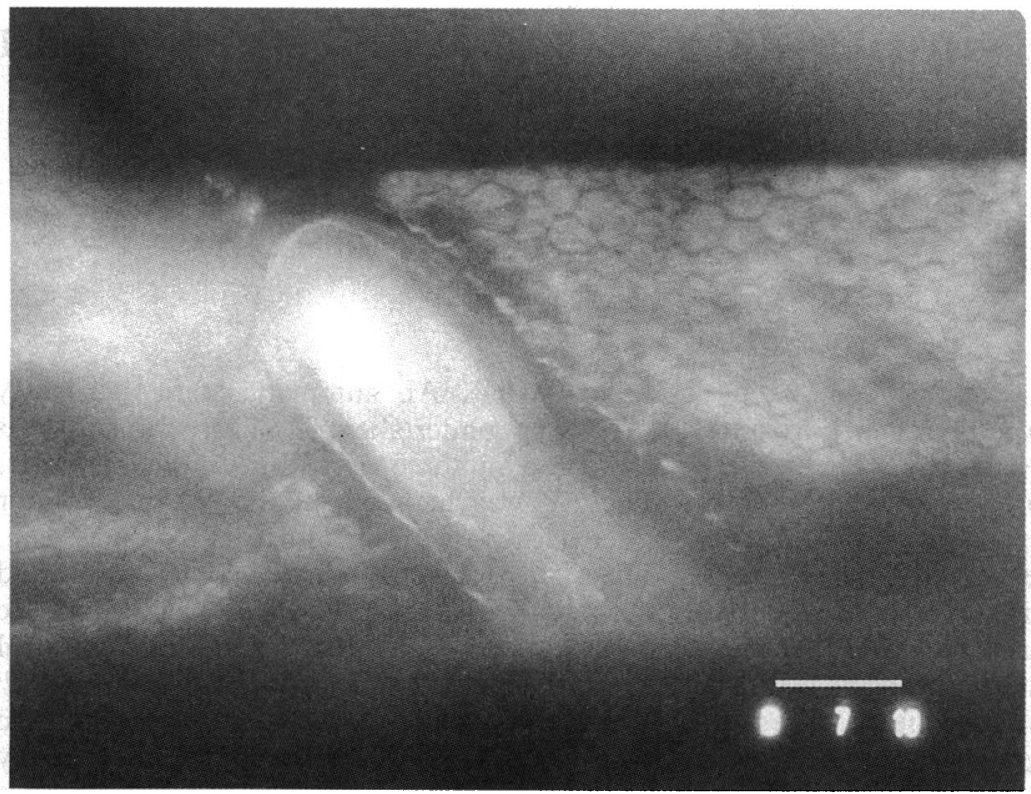

Figure 3 Specular microscopy of the left eye showing the cross section of a cylindrical foreign body embedded in a corneal scar. The adjacent corneal endothelium shows a lowered endothelial cell count of 750 cells $/ \mathrm{mm}^{2}$ with moderate pleomorphism and polymegathism. (Bar=100 $\mu \mathrm{m}$.)

ever, in long-standing quiescent cases removal may be deferred and the patient observed.

Pallor of the lash has been noted previously. ${ }^{134}$ Under the high magnification of specular microscopy this pale appearance was consistent with an encrusted deposit on the lash, suggesting a very low grade reaction which is probably biochemical rather than cellular.

The endothelial cell count in the present case was much lower than would be expected from a relatively minor penetrating injury. The low count may be due to surgical trauma, but the small wound with only one lash removed makes this unlikely. Alternatively the low endothelial cell count may represent a long-term low grade reaction to the presence of the lash, either an irritant biochemical effect associated with the crusting of the lash or a mechanical effect from its contiguity with the endothelium. No cellular inflammatory response was present.

This case re-emphasises the ability of the eye to tolerate almost indefinitely the presence of an eyelash foreign body with retention of normal visual function provided the lash follicle is not present, but it points to a disproportionate effect on the corneal endothelium which needs to be monitored.

This work was carried out under Research Projects 92 and 99 of the Royal Victorian Eye and Ear Hospital. It was supported in part by the Eye Ear Nose and Throat Research Institue, 126 Victoria by the Eye Ear Nose and Throat Research Institue,
Parade, East Melbourne, Victoria 3002, Australia.

1 Duke-Elder S, ed. System of ophthalmology. Mechanical injuries. London: Kimpton, 1972; 14: 553-60.

2 Steahly MLP, Galas CSM. Eyelash tolerated in the anterior chamber and cornea. Ann Ophthalmol 1976; 8: 971-3.

3 Gradle HS, A cilium in the anterior chamber for nineteen years. Am $\mathcal{F}$ Ophthalmol 1923; 6: 764 .

4 Sharpe OA. Cilia in the anterior chamber. Am $\mathcal{f}$ Ophthalmol 1925; 8: $301-6$.

5 Hughes RA. A cilium thru the iris without symptoms. Am fOphthalmol 1924; 7: 702.

6 Rubey von F. Wimpern in der Vorderkammer. Klin Monatsbl Augenheilkd 1966; 149: 371-3.

7 Donaldson DB. Atlas of extermal disease of the eye. Anterior chamber, iris and ciliary body. St Louis: Mosby, 1973; 4 65-6.

8 Kozart DM, Yanoff M, Katowitz JA. Tolerated eyelash embedded in the retina. Arch Ophthalmol 1974; 91: 235-6.

9 Fortuin MEHM, Blanksma LJ. An unusual complication of perforating wounds of the eye. Doc Ophthalmol 1986; 61: perforating

10 Gottlieb F, Finestone J, Ackerman JL. Intravitreal cilia and retinal detachment. Ann Ophthalmol 1982; 14:541-6.

11 Fish LA, Ragan MT, Smith RE, Lean J. Propionibacterium acnes lens abscess after traumatic implantation of intralenticular cilia. Am $\mathcal{F}$ Ophthalmol 1988; 105: 423-4.

12 Joseph AL. Cilia in the anterior chamber. Report of a case. Eye Ear Nose Throat Monthly 1967; 46: 188-9. 